\title{
MEMÓRIA CIENTÍFICA AMAZONENSE: Reflexões sobre os arquivos pessoais de cientistas
}

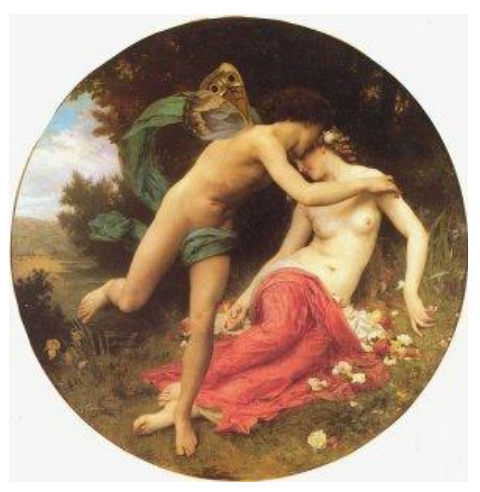

Rodolfo Almeida de Azevedo

Kátia Viana Cavalcante

Marcos Araíjo Silva

\section{Resumo}

O presente artigo visa discutir o conceito de memória científica no Amazonas, mais particularmente arquivos pessoais de cientistas, levando em consideração o conceito de lugar de memória e memória coletiva. Temática ainda pouco discutida no âmbito acadêmico nacional. Para isso, verificou-se como essa memória científica foi preservada no passado, mediante observação da trajetória de vida de alguns cientistas amazonenses, selecionados a partir de sua importância como pensadores no âmbito regional, vinculados a instituições de ensino superior e institutos de pesquisa. Cientistas, esses que pensaram e pensam as realidades amazônicas, como Mário Ypiranga Monteiro, Samuel Benchimol, Milton Hatoum e Renam Freitas Pinto. Entretanto, tomou-se como exemplo o caso da Biblioteca e Arquivo Arthur Cezar Ferreira Reis, que apesar de recente, já serviu de campo de pesquisa para monografias, dissertações e teses. Diante disso, contatou-se que não há políticas de preservação da memória científica no Amazonas, e os poucos acervos pessoais preservados são casos isolados, fazendo-se necessário refletir sobre essa realidade, bem como discutir politicas publicas voltadas para salvaguardar a memória científica no Amazonas.

Palavras-chave: Memória. Arquivos pessoais. Cientistas.

\begin{abstract}
This paper discusses the concept of scientific memory in the Amazon, more particularly personal files scientists, taking into account the concept of place of memory and collective memory. Theme little discussed in the national academic context. For this, it was found that as scientific memory was preserved in the past by observing the life histories of some Amazonian scientists, selected from its importance as thinkers at the regional level, linked to higher education institutions and research institutes. Scientists, those who thought and think Amazonian realities, like Mario Ypiranga Monteiro, Samuel Benchimol, Milton Hatoum and Renam Freitas Pinto. However, we took as an example the case of the Library and Archives Arthur Cezar Ferreira Reis, who despite recent, has served as a field
\end{abstract}


of research for papers, dissertations and theses. Therefore, we contacted that there are no policies for preserving scientific memory in the Amazon, and the few personal collections preserved are isolated cases, making it necessary to reflect on this reality, as well as discussing public policies geared to safeguard scientific memory on Amazon.

Keywords: Memory. Personal file. Scientists.

\section{Introdução}

A presente temática surgiu no âmbito de discussões extraclasse entre colegas e professores ao refletirmos sobre a perda da memória científica no Estado do Amazonas. As universidades e instituições de pesquisas localizadas no Estado do Amazonas não possuem políticas de recolhimento e preservação de acervos pessoais, mesmo se tratando de personalidades públicas, ou cientista, no caso das Universidades e Institutos de Pesquisa. Diante disso, o objetivo desse ensaio é refletir sobre a necessidade de pensar essa realidade, revelar esse problema e suas consequências.

Para tal empreitada, se faz necessário esclarecer alguns procedimentos, na qual partimos do entendimento de que o conceito de memória científica encontra-se associado ao conceito de arquivos científicos, particularmente arquivos pessoais de cientistas, visto que, os arquivos preservariam a memória desses personagens, uma memória materializada nos mais variados suportes.

Os arquivos pessoais se encontram em uma linha tênue no que concerne ao pessoal e ao coletivo, ao público e ao privado, tornando-se, em alguns casos impossível sua dissociação, assim como o conceito de memória individual e memória coletiva apresentadas por Halbwachs (1990), pois as memórias individuais não seriam apenas de um indivíduo, uma vez que suas lembranças apenas existiram se correlacionadas aos grupos a que pertenceu.

Seguindo critérios de relevância de importância como pensadores da realidade amazônica, bem como a vinculação a Instituição de Ensino Superior ou a Institutos de pesquisa, foram selecionados 04 (quatro) 
autores, dos quais dois encontram-se falecidos. Mediante estudo de sua trajetória de vida, poderão corroborar para esclarecermos alguns pontos, são eles: Samuel Benchimol, Mário Ypiranga Monteiro, Milton Hatoum, Renan Freitas Pinto, que dedicaram parte de suas vidas em prol da pesquisa científica.

De maneira resumida traçaremos minibiografias dos autores objetivando ressaltar a importância dos mesmos para entender suas obras. Diante desse relato surgem alguns questionamentos como, por exemplo, está sendo preservada a memória dos cientistas amazonenses? Como poderemos entender e compreender a trajetória intelectual desses autores? Será se apenas analisando suas obras os compreenderemos em profundidade?

Ponderando tais indagações, entendemos que ao conhecer apenas as obras desses autores não poderemos compreender realmente a formação do pensamento daquele indivíduo, pois, necessitou-se de um processo complexo, não linear, de discussões, leituras, fichamentos, rascunhos e infinitas contribuições até que se chegar ao resultado final. Faz-se necessário conhecer esse processo para que se possa compreender realmente aquele autor enquanto individuo pensante, representante de um tempo histórico, bem como aos vários grupos sociais que direta ou indiretamente o influenciaram.

Dentre centenas de intelectuais que já escreveram sobre a Amazônia, apenas um caso pode ser considerado exceção, no que concerne a preservação da memória, trata-se de Arthur Cezar Ferreira Reis, historiador de renome nacional e ex-governador de estado do Amazonas uma vez que, sua biblioteca particular encontra-se hoje aberta ao publico, bem como o seu arquivo pessoal pode ser consultado. Garantindo desta forma um dos princípios básicos que rege a Arquivística, ou seja, " $a$ indivisibilidade ou integridade arquivisticas que diz que os fundos de arquivo devem ser 
preservados sem dispersão, mutilação, alienação, destruição não autorizada ou adição indevida" (BELLOTTO, 2002, p. 21).

Diante do caso isolado do Arquivo e Biblioteca Arthur Reis, faz-se necessário pensarmos também em Biblioteca e Arquivo Mário Ypiranga Monteiro, Álvaro Botelho Maia, Djalma Batista, pesquisadores esses que contribuíram, em suas respectivas áreas, para o desenvolvimento científico da região e hoje encontram-se apenas eternizados em nomes de ruas da cidade. Mas porque limitarmo-nos a pensar apenas em pesquisadores/cientista que já contribuíram para o desenvolvimento da Amazônia? Claro que podemos ampliar essa perspectiva e incluir autores que ainda pensam a Amazônia, como Renan Freitas Pinto, Neide Gondin, Marilene Correa entre outros que apenas de sua importância científica, são conhecidos apenas no âmbito da academia.

\section{Concepção de Memória}

Em entrevista do professor Mário Ypiranga Monteiro, no ano de 1994, ao programa Via de Regra ${ }^{1}$, apresentado pela jornalista Norma Araújo, é questionado, como ele se fez historiador em uma cidade sem memória? Bastante incisivo Mario Ypiranga discordou da opinião, e argumentou que:

A cidade tem sim memória, memória viva, tem memória ativa, tem memória material, tem memória sentimental e tem memória livresca, você passa pela praça de são Sebastião e vê dois monumentos que são dois museus de arte, o teatro amazonas é um museu, ele tem uma historia, ele conta uma historia, e o monumento das Aberturas dos Portos que também é uma unidade museologia importante, porque tem uma história e conta uma história. (MONTEIRO, 1994)

Nessa perspectiva nos deparamos com um conceito de memória que se aproxima do que Pierre Nora denomina de lugares de memória

${ }^{1}$ Programa cujo objetivo era resgatar a memória da cidade de Manaus, através de depoimentos de personalidades que fizeram a historia da cidade de Manaus. 
(1981). Ainda segundo Nora, "esses lugares de memória nascem e vivem do sentimento que não há memoria espontânea, que é preciso criar arquivos, que é preciso manter aniversários, organizar celebraçoes, pronunciar elogios fúnebres, notariar atas, porque essas operações não são naturais" (NORA, 1981, p. 13).

Talvez seja compreensivo porque hoje os monumentos citados por Mario Ypiranga não são reconhecidos por grande parte da população enquanto representantes de uma época áurea da cidade de Manaus. Nem identificado como memória, pois há a necessidade de se estar continuamente relembrando o verdadeiro significado desses monumentos. Ainda seguindo o raciocínio de Mario Ypiranga, percebemos que o autor traz a tona materiais da memória (LE GOFF, 1990, p. 535), ou seja, documentos e monumentos. Le Goff diferencia-os tratando os documentos, numa perspectiva da escola histórica positivista em que o primeiro se oporia ao segundo no sentido da intencionalidade, e o monumento teria sido criado com o único objetivo de se perpetuar no tempo.

Ainda para Le Goff, "A memória, como propriedade de conservar certas informações, remete-nos em primeiro lugar a um conjunto de funções psíquicas, graças às quais o homem pode atualizar impressões ou informações passadas, ou que ele representa como passadas" (LE, GOFF, 1990, p. 423)

Analisando a conceituação apresentada por Jacques Le Goff, concluímos que podemos associar o conceito de memória ao de arquivo, pois esses últimos têm como objetivo preservar certas informações, bem como associar ao conceito de lugares de memória proposto por Pierre Nora, já que esses lugares têm também o objetivo de conservar informações do passado.

Os estudos empreendidos por Maurice Halbwachs (1990) contribuíram definitivamente para a compreensão dos quadros sociais que compõem a memória. Para ele a memória aparentemente mais particular remete a um grupo. O indivíduo carrega em si a lembrança, mas está 
sempre interagindo com a sociedade, seus grupos e instituições. É no contexto destas relações que construímos as nossas lembranças. A rememoração individual se faz na tessitura das memórias dos diferentes grupos com que nos relacionamos.

Fazendo associação do conceito de memória como o conceito de arquivo, que vem a ser conjunto de documentos, independente do suporte, produzidos ou recebidos por pessoa física ou jurídica no decorrer de suas atividades, podemos inferir que ao preservarmos os arquivos, estamos preservando a memória institucional, memória de um lugar ou mesmo memória de uma pessoa.

Para a presente reflexão nos deteremos a abordar os arquivos pessoais. Esse são conjuntos de documentos produzidos e acumulados por pessoa física durante a vida, como fotos, textos, cartas, objetos que guardam em sim grande carga de testemunho da vida e da obra do seu titular. Esse tipo de documento tende, na maioria das vezes a desaparecer, pois, em muitos casos os familiares não têm condições econômicas ou interesse em manter esta documentação preservada.

Belloto (2004) traz a conceituação dos arquivos pessoais como embutida na própria concepção de arquivos privados, pois se tratam de papeis produzidos e recebido por entidade ou pessoas físicas de direito privado. Estes documentos refletem a personalidade e o comportamento do seu produtor, e está ligado ao cotidiano, a atuação cultural, política e econômica, de quem a produziu.

Percebemos que há uma aproximação entre os arquivos pessoais, que não são completamente pessoais, pois possuem documentos que, teoricamente, pertenceriam a instituição a qual o titular contribuiu por determinado tempo, com o conceito de memória coletiva, na qual esta só poderia ser entendida se associada a coletividade ou ao grupo a qual pertenceu.

Os arquivos pessoais, ou melhor, os arquivos pessoais de cientistas 
que é o objeto desse ensaio, se enquadra dentro de uma hierarquia, que são os arquivos científicos. Entretanto, não há ainda um consenso por parte dos especialistas na área do que seriam os arquivos científicos. Santos (2008) argumenta que os arquivos científicos seriam todas as fontes arquivísticas que permitem estudar a evolução das políticas de pesquisa e de ensino científico. A evolução desta ou daquela disciplina ou ainda o papel deste ou daquele cientista no desenvolvimento do conhecimento.

Silva (2005, p.6) acrescenta a esse conceito, dizendo que a bibliografia considera arquivo científico todas às fontes arquivísticas oriundas da prática científica e tecnológica, que permitem a verificação do crescimento e desenvolvimento das políticas e ensino científico, dos avanços das diferentes disciplinas e, também, da contribuição de cientistas para a sua área de atuação.

Contudo, os arquivos e arquivos pessoais possuem algumas especificidades que devem ser levadas em consideração quando forem organizadas, avaliadas, dentre outras atividades que são realizadas. Essas singularidades característica dos arquivos pessoas devem ser analisadas levando em consideração tais fatores, bem como a própria conjuntura em que seu produtor se encontra.

A necessidade de espaço obriga a selecionar materiais a serem preservados, e sem o necessário conhecimento destruiremos a memória de instituições ou mesmo de pessoas.

Segundo Maria Celina Soares Mello e Silva (2005, p 06), os Arquivos científicos se dividiriam em três categorias:

- Os arquivos de organismos de administração de políticas e de fomento;

- Arquivos de instituições de pesquisa e ensino;

- Arquivos pessoais de cientistas, formados pelos documentos produzidos e guardados pelo cientista no decorrer de sua trajetória de vida. 
Ao se considerar a proposta de Mello e Silva, identificamos os arquivos pessoais de cientistas como de maior relevância, pois nestes, não é encontrado apenas o resultado final de uma pesquisa, como nos arquivos de instituições de pesquisa e ensino e nas organizações de políticas e de fomento. Entendemos que os arquivos pessoais de cientistas poderão ser mais completos, pois contém informações que não estão diretamente ligados a determinado fato, mas é essencial para entendermos a mentalidade e a formação do pensamento daquele cientista.

\section{Pensadores da Amazônia}

Desde que a Amazônia foi descoberta, invadida, conquistada ou inventada, segundo a concepção dos mais variados autores é que se tem pensado sobre ela, seja com objetivos econômicos, religiosos, políticos ou simplesmente curiosidade diante do desconhecido. Nessa perspectiva, citamos as obras dos cronistas que por aqui passaram como Charles La Condamine que percorreu o Alto Solimões de 1739 a 1743, Alexandre Rodrigues Ferreira cuja sua viagem filosófica foi de 1783 a 1792, Wallace já no século XIX, de 1848 a 1852, Agassiz, de 1865 a 1866, entre outros.

Segundo a autora Neide Gondin, esses autores pensaram a Amazônia sob um olhar já construído, olhando apenas o que vinha reafirmar o que já haviam pré-concebido (GONDIN, 2007), sendo necessário observar tais direcionamentos, suas reais intencionalidades. Diante disso, surgem alguns questionamentos, não seria interessante se tivéssemos acesso aos rascunhos, as anotações desses expedicionários? Não supririam algumas lacunas que surgem ao ler suas obras? Temos certeza que inúmeras questões seriam respondidas.

A partir do século XX, pesquisadores da região começam a pensar a Amazônia, Mário Ypiranga Monteiro é um deles. Nascido em Manaus, é reconhecido nacional e internacionalmente enquanto geógrafo pela sua pesquisa monográfica intitulada O Sacado (1964). Na qual enquanto 
geógrafo analisa esse fenômeno que corresponde ao "processo de escavação mecânica e alteração da fácies bidrográfica pela coalescência das curvas do rio" (MONTEIRO, 1964, p.9)

Entretanto, Mário Ypiranga não se limitou aos estudos geográficos, foi historiador, etnólogo, jornalista, professor e advogado, produzindo uma vasta literatura nessas áreas e contribuindo desta forma para consolidação das pesquisas científicas na Amazônia.

Na obra Acadêmicos Imortais do Amazonas, o historiador Almir Diniz discorre sobre a vida intelectual de Mario Ypiranga Monteiro:

Pertenceu ao Instituto Geográfico do Amazonas, à Academia de Artes Y Letras de Cuba, à Associação Tucumana de Folklore da Argentina, à Academia Dominicana de la História de San Domingos, à The Academy of Political and Social Science de Philadelphia (USA), e à Associação dos Escritores do Amazonas entre outras vinculações. Dentre suas obras podemos citar: O Aguadeiro, 1947/79; In Memória de Cid Lins, 1946; O Estado Social do índio Brasileiro, Manaus, 1946; Fundação de Manaus, 1948/52; Quarta Orbis Pars, 1950; A Capitania de São José do Rio Negro, 1955; O Regatão, 1957; A Catedral Metropolitana de Manaus, 1956; Teatro Amazonas (3. Vol.), 1965/66; Roteiro do Folclore Amazônico, 1964; Síntese Histórica da Política Militar do Amazonas, 1972; O Sacado, 1966 entre outras inúmeras obras (DINIZ, 2002, p. 151-152).

Participou da Ordem dos Advogados do Brasil, da Academia Amazonense de Letras e da National Geographic. Sua obra Alimentos Preparados à Base de Mandioca foi premiado pelo Instituto Brasileiro de Folclore, bem como outros livros que também receberam prêmios.

Mediante a observação dessa minibiografia, podemos inferir que Mário Ypiranga apoiou-se em vários suportes informacionais para produzir suas obras tais como: Livros, artigos, músicas, objetos museológicos, dentre outros. No contexto em que o autor se encontrava a divulgação científica não era tão extensa como na atualidade, logo, presume-se que muitas de suas pesquisas não chegaram a ser publicados, mas que podem ser essenciais para compreendê-lo mais profundamente. Entretanto, apenas a 
biblioteca de Mário Ypiranga encontra-se preservada e disponibilizada a consulta pública.

Outro grande pensador da Amazônia foi Samuel Isaac Benchimol, nascido em Manaus, falecido em 2002. Escreveu aproximadamente 109 trabalhos, foi membro da Academia Amazonense de Letras, foi professor Emérito da Universidade do Amazonas, onde lecionou por mais de 50 anos, foi pesquisador, economista, líder comunitário e empresário.

Samuel Benchimol foi um homem além de seu tempo a ponto de propor uma reorganização do espaço político brasileiro. Na obra Amazônia: Um pouco-antes e além-depois (2010), pode-se encontrar essa proposta intitulada Projeto Samuel Benchimol (1966), que segundo o próprio autor "foi esboçado em dois volumes: Estrutura Geossocial e Econômica da Amazônia, e posteriormente, Política e Estratégia na Grande Amazônia Brasileira e As Oito Amazônias dos 24 Estados e Território: Uma Reformulação" (BENCHIMOL, 2010, p. 795).

Segundo Baze (2012, p. 18) o professor Samuel Benchimol e sua família

incluem-se no álbum dos pioneiros que "fizeram" a Amazônia e deram sua contribuição para que ela se tornasse mais próspera, mais conhecida e mais amada. Beberam de suas águas, ficaram raízes nesta terra abençoada e aqui deram sentido a suas vidas e acalentaram seus sonhos.

É considerado um dos maiores especialistas da região amazônica, sua principal contribuição foi o estudo dos aspectos sociais envolvidos na economia da região e no desenvolvimento sustentável da Amazônia. Faleceu no ano de 2002.

Quando ao valioso arquivo e biblioteca Samuel Benchimol, encontra-se sob a custódia da família. Tal acervo foi organização por sua sobrinha, a bibliotecária Denise Benchimol, e já foram objeto de estudo de alguns pesquisadores, cujo acesso é permitido mediante liberação dos custodiadores, no caso, seus familiares. 
Dentre os pensadores ativos, pode-se citar Milton Hatoum, nascido em 19 de agosto de 1952 na cidade de Manaus, é considerado uma dos grandes escritores vivos do Brasil. Descendente de libaneses, ensinou literatura na Universidade Federal do Amazonas (UFAM), e na Universidade da Califórnia em Berkeley, escreveu inúmeros romances, cujos mais destacados são Relato de um Certo Oriente, Dois Irmãos, Cinzas do Norte e Órfãos do Eldorado.

$\mathrm{Na}$ obra Dois Irmãos, Hatoum descreve muito bem a realidade Amazônia, podendo ser percebida as seguintes temáticas: a imigração para Manaus, os costumes, as rotinas de uma cidade que passava por inúmeras transformações, bem como a temática da religião, as relações de criadagem que havia, entre outras, colocando-o como leitura indispensável para se conhecer esses meandros da vida da sociedade manauara.

Outro grande pensador da Amazônia é Renan Freitas Pinto, graduado em Letras (língua e literatura inglesa) e Doutor em Ciências Sociais pela Pontifícia Universidade Católica de São Paulo - PUC/SP e Pós-doutorado em Filosofia pela Universidade de São Paulo - USP².

Dentre as obras de Freitas Pinto cita-se: Amazônia: a natureza dos problemas e os problemas da natureza (2005), Viagem das Idéias(2006), O Diário do Padre Samuel Fritz. (org.) (2006), Voẓes da Amazônia: Investigação sobre o pensamento social brasileiro (org.) (2007) e, não menos importante, A Sociologia de Florestan Fernandes (2008).

A obra A Sociologia de Florestan Fernandes foi esta ultima obra foi publicada pela Editora da Universidade do Amazonas - EDUA e trata-se da pesquisa de doutorado onde Freitas Pinto defende incisivamente Florestan Fernandes como o pioneiro da sociologia crítica no Brasil, destacando suas contribuições no campo da teoria sociológica e do pensamento brasileiro.

\footnotetext{
${ }^{2}$ Dados retirados do currículo lattes, http://buscatextual.cnpq.br/buscatextual/visualizacv.do?id=K4792527Y4
} 
Neste rol de pesquisadores podemos incluir outras centenas, entretanto o objetivo aqui é apontar que por detrás de suas brilhantes obras encontram-se processos evolutivos ideias. Portanto, para entender mais profundamente tal pesquisador, faz-se necessário conhecê-lo nesses meandros de sua história, conhecer com quem se comunicavam, quais eram suas referencias entender o como se estabelece o processo de criação científica.

\section{Arquivo/Memórias de Arthur Cezar Ferreira Reis}

Arthur Reis não se diferencia de outros políticos e intelectuais, não podemos afirmar que estava além de seu tempo, na verdade era um homem de seu tempo, foi criado para seguir carreira na política como a maioria dos jovens de sua época, pelo menos os jovens de família abastada, na qual a família de Arthur Reis se enquadrava.

Arthur Cezar Ferreira Reis, filho do jornalista Vicente Torres da Silva Reis e de Emília Ferreira da Silva Reis, cresceu e se educou na capital da borracha durante seu período de crise, de onde se mudou para Belém em 1939 e depois para o Rio de Janeiro em 1945, construindo uma carreira que o consolidaria como especialista em assuntos amazônicos (SOUSA, 2009, p. 08).

Diniz (2002, p. 126) descreve que Arthur Reis, com mais de 90 títulos publicados, avulta-se no cenário intelectual do Amazonas, com projeção no Brasil e no exterior, como astro de primeiríssima grandeza. Iniciou o curso jurídico em Belém, continuou em Manaus e o concluiu no Rio de Janeiro, na Faculdade de Ciências Jurídicas e Sociais da Universidade do Rio de Janeiro, Bacharelando-se a 11 de agosto de 1927.

Todavia SOUSA (2009, p. 16) divide a trajetória de Arthur Reis em três momentos: 
$1^{\circ}$ ) De 1920 a 1938 - momento que vai de sua inicial busca profissional, cursando Direito e escrevendo pequenos textos de história à edição do seu primeiro grande trabalho intitulado História do Amazonas, seguido de outros trabalhos importantes como Manáos e outras villas.

2) De 1939 a 1945 - do ano que se transfere para Belém, travando novas e importantes relações pessoais em busca de sua ascensão profissional à sua transferência para o Rio de Janeiro que marcou um período de apogeu, visto que era comum entre os intelectuais do Norte e do Nordeste ansiar por uma boa colocação nos quadros intelectuais do Sul.

$3^{\circ}$ ) E de 1946 a 1990 - momento em que se estabeleceu no Rio de Janeiro como Diretor Geral da Divisão de Expansão Econômica do Departamento de Administração do Ministério do Trabalho, passando depois por diversos cargos sempre conciliados com ao trabalho de produção historiográfica, que culminou com a publicação de seu mais célebre trabalho A Amazônia e a Cobiça Internacional.

A sua infância e juventude, a conjuntura do fausto da borracha em que Arthur Reis nasceu, Ribeiro (2012) argumenta a sedução desse fausto, a ponto de aceitarem a miséria e aos de famílias abastadas livrarem-se da culpa pela tragédia dos seringueiros. É nessa conjuntura que cresceu Arthur Reis desde novo direcionado a ser grande.

Convém destacar uma matéria publicada em 08 de janeiro de 1920 no Jornal do Comércio, de propriedade de seu pai, na Coluna "Manaus Social", onde apresentava os aniversariantes do dia.

Arthur Reis, como filho do proprietário do jornal, recebeu um espaço ainda maior em relação aos comumente concedidos às pessoas de destaque na sociedade manauense, revelando a dimensão do anseio de seu pai em incluí-lo entre os notáveis, ao atribuir-lhe grande número de admiradores (SOUSA, 2009, p. 9) 
Arthur Reis era, portanto, apresentado, apesar da pouca idade, como uma promessa propensa ao cultivo de ideias nobres e elevadas, um belo exemplo de virtude e civismo que já possuía não poucos admiradores.

Ribeiro (2012) enfatiza que a ideologia política em vigor, isto é, a geopolítica que tinha como objetivo a integração da região, sempre de maneira desastrosa para o meio ambiente, sem levar em consideração as especificidades regionais como foi o caso do extrativismo das drogas do sertão e da borracha.

É com o projeto nacional desenvolvimentistas que é criada as condições institucionais para a integração da Amazônia à economia brasileira, no qual a Superintendência do Plano de Valorização Econômica da Amazônia (SPVEA) "representou o marco de intervenção estatal para superar a inércia da economia extrativa" (RIBEIRO, 2012, p.14).

Arthur Reis foi diretor da SPVEA de 1953 a 1955 (DINIZ, 2002, p. 126). Este órgão, segundo SOUZA (2009, p. 321) tinha por objetivo aplicar $3 \%$ (três por cento) do total dos impostos recolhidos em todo o Brasil em projetos de desenvolvimento da região. Entretanto, não obteve sucesso, pois insistia no extrativismo, bem como em linhas de crédito bancário, direcionando créditos quase apenas para a borracha, excluindo outras atividades, como a juta e a pimenta-do-reino.

Destaca-se esta passagem de Arthur Reis na direção da SPVEA, pois em seu arquivo pessoal encontra-se 06 (seis) caixas com documentos que dizem respeito a esse Órgão, mas que também pertencem ao seu diretor, neste caso Arthur Reis. Reafirmando com isto, a prática comum na administração pública, quando um cidadão deixa de exercer determinado cargo público, leva com ele os documentos que seriam de caráter público, pois não há uma real distinção, nesse caso, entre o que é de caráter público e o que é privado.

Em 1955, mesmo ano que deixa a direção da SPVEA, assume a direção do Instituto Nacional de Pesquisas da Amazônia (INPA). Este 
havia sido criado em 29 de outubro de 1952, pelo Decreto no 31.672, sendo instalado em 27 de julho de 1954, tendo como primeiro diretor Dr. Olympio Ribeiro da Fonseca Filho. Sendo Arthur Reis o segundo diretor do instituto.

Durante sua gestão o INPA é reestruturado passando de 06 (seis) Divisões para 02 (duas) e é integrado a ele um Centro de Pesquisas Florestais, que tinha uma organização peculiar, pois pertencia à Superintendência do Plano de Valorização Econômica da Amazônia (SPVEA) e que fora confiada ao INPA para montagem e funcionamento (RODRIGUES, 1981, p. 8). Dentro de estratégias de construção nacional no Brasil, que implicaram um processo de nacionalização.

Foi com este interesse minimamente comum que a Ciência foi instituída no Amazonas mediante da fundação do INPA, apresentando-se como uma instituição pioneira no sentido de tomar para si, do ponto de vista de uma política científica nacional, uma conjunção de projetos internacionais, estaduais e locais.

Arthur Cezar Ferreira Reis, no seu relatório institucional de 1956, define a Amazônia como "um mundo por descobrir e identificar", "um espaço aberto à ousadia dos mais dispostos".

Durante representação do Brasil na Conferência de Comércio de Desenvolvimento das Nações Unidas, em Genebra, toma conhecimento de sua eleição para o cargo de governador do Amazonas. Tornando-se o primeiro governador do Amazonas no período da Ditadura Militar Brasileira. Ressalva-se que pesar da carreira política, este nunca abandonou a pesquisa, contribuindo para as mais diversas áreas.

\section{Biblioteca e Arquivo Arthur Cezar Ferreira Reis}

No Amazonas, apenas um exemplo foge à exceção, em se tratando de preservação de arquivo pessoal, trata-se da Biblioteca e Arquivo Arthur 
Cezar Ferreira Reis, criado no ano de 2001, localizada na Av. 7 de setembro, $\mathrm{n}^{\circ}$ 444, Centro de Manaus, entretanto com perspectiva de mudanças para o Centro Cultural Povos da Amazônia.

O acervo reúne as obras que compunham a biblioteca particular de Arthur Reis, são compostos por 21 mil títulos que estão disponíveis em dois suportes técnicos: coleção de livros e coleção de periódicos, abrigando também o arquivo pessoal, que contém desde documentos oficiais, até cartas de caráter pessoais.

O acervo está disposto em 249 caixas-arquivo que contém documentos que vão desde 1920 até 1990, nesse caso correspondências expedidas e recebidas. Encontram-se também cópias de livros de outros autores e manuscritos dos livros de Arthur Reis com anotações de próprio punho. Documentos esses que podem auxiliar ou traçar o processo de criação de uma obra, contribuindo desta forma assim pra o desenvolvimento da área da história das ideias.

Esse Acervo já foi objeto de inúmeras pesquisas, na qual podemos destacar a dissertação de mestrado em História Arthur Reis e a História do Amazonas: um início em grande estilo (2009) da historiadora Lademe Correa de Sousa, que, por meio da analise da correspondência pessoal de Arthur Reis, pode concluir que ele estava em permanente contato com intelectuais renomados no âmbito nacional, como Sergio Buarque de Holanda e Gilberto Freire, bem como outros intelectuais.

Outra pesquisa que merece destaque é a dissertação de mestrado em historia intitulada Movimentos Sociais na Obra de Arthur Reis, defendida em 2009, pela historiadora Leila Margareth Rodrigues Gomes, onde a autora utiliza além as obras de Artur Reis, alguns documentos contidos em seu acervo, como: processos, bem como cartas de agradecimento em nome do então Governador, documentos esses essenciais para alcançar seu objetivo que era traçar o amplo conjunto das representações dos movimentos sociais da Amazônia na obra de Arthur Reis. 
Essas e outras pesquisas servem para nos mostrar a importância desses acervos como campo de pesquisa, bem como para perenizar a memória de personalidades que dedicaram parte de suas vidas em benefício da pesquisa científica.

\section{Considerações Finais}

O Brasil e particularmente a capital do Amazonas está passando por um processo de desvalorização de sua memória documental, podemos afirmar isso ao observar os arquivos públicos, no presente caso, o arquivo Estadual e o arquivo Municipal. No que refere a memória científica do Amazonas não é diferente, como se pode averiguar por meio da análise das biografias dos referidos cientistas, que apesar de sua importância para o desenvolvimento científico são perdidos nas brumas do tempo.

Nesse contexto, foi ressaltado o caso da Biblioteca e Arquivo Arthur Reis, que apesar de ser uma exceção, é um local que preserva os documentos produzidos e recebidos pelo seu produtor, servindo como campo de pesquisa para monografias, dissertações e teses. Percebemos com esse caso, a importância de preservamos acervos documentais de cientistas.

Diante do objetivo do presente ensaio, cujo principal era refletir sobre a memória científica do Amazonas, ressaltamos a necessidade de pensar essa realidade, revelar esse problema e as suas consequências, cujo principal é a perda da memória da cidade e mesmo do Estado, bem como a perda da própria história de uma sociedade.

Portanto, compreendem-se como de grande importância os arquivos científicos, principalmente os arquivos pessoais de cientistas, por conterem informações únicas, essenciais para traçar a evolução do conhecimento ciência, contribuindo assim para o desenvolvimento da história da ciência.

Dentre os motivos observados para preservação de memória documental, pode-se destacar: Dar o mérito a esses cientistas que 
dedicaram parte de suas vidas em prol da pesquisa científica, o segundo ponto é contribuição que a documentação produzida e recebida por tais cientistas pode trazer para o desenvolvimento da ciência, nas mais variadas áreas.

Entendemos que os arquivos pessoais não possuem apenas um caráter pessoal, mas são construídos na base de relações, entre correspondências recebidas e expedidas, representantes não apenas de uma memória individual, mas de uma memória coletiva, do grupo ou dos grupos a que pertenceram. Esses arquivos também guardam intrinsecamente informações que são de grande relevância para a compreensão da formação do pensamento dos indivíduos.

Assim sendo, espera-se que o presente trabalho contribua para uma reflexão maior, em conjunto com as autoridades competentes sobre a importância da preservação dos arquivos pessoais, sejam de cientistas, de políticos, de médicos ou outros cidadãos, pois, não apenas estaremos preservando a memória individual, mas uma memória coletiva, uma memória social. Preservando a trajetória de vida desses pensadores estaremos contribuindo para preservação do pensamento social amazônico e porque não dizer brasileiro.

\section{Referencias}

BAZE, Abrahim. Samuel Isaac Benchimol: Ensaio biográfico de um educador e empresário. Manaus: Ed. Valer, 2012.

BELLOTTO, Heloisa Liberalli. Arquivistica: Objetos, Princípios e Rumos. São Paulo: Associação dos Arquivistas de São Paulo, 2002.

BELLOTTO, Heloísa L. Arquivos permanentes: tratamento documental. 2. Rio de Janeiro: Editora FGV, 2004.

BENCHIMOL, Samuel. Amazônia: Um pouco-antes e além-depois. 2a edição revisada. Manaus: Edua, 2010. 
DINIZ, Almir. Acadêmicos: imortais do Amazonas DICIONARIO BIOGRÁFICO. Manaus: Ed. Uirapuru, 2002.

GOMES, Leila Margareth Rodrigues. Movimentos Sociais na Obra de Arthur Reis. Dissertação de Mestrado. Manaus(Programa de Pós-Graduação em História/ UFAM) 2009, $150 f$.

GONDIM, Neide. Invenção da Amaz̧ônia. Manaus: Ed. Valer, 2007.

HALBWACHS, M. A memória coletiva. São Paulo: Vertice, 1990.

LE GOFF, Jacques. História e Memória. Tradução Bernardo Leitão. Campinas, SP Editora da UNICAMP, 1990.

MONTEIRO, Mário Ypiranga. O Sacado - Morfodinâmica Fluvial. Cadernos da Amazônia. Manaus: CNPq- Instituto Nacional de Pesquisa da Amazônia, $1964,38 \mathrm{p}$.

MONTEIRO, Mário Ypiranga. Mario Ypiranga Monteiro. Entrevista[1994]. Entrevistador: Norma Araujo. Manaus: Programa Via de Regra, 1994. Disponível em: http://www.youtube.com/watch?v=yqOnMe4Ca8w. Acesso em: 28/11/2013

NORA, Pierre. Entre Memória e História: A problemática dos Lugares. Trad. Yara Aun Khoury. In.: Projeto História: Revista do Programa de PósGraduação em História e do Departamento da PUC-SP. São Paulo, SPBrasil, 1981.

RIBEIRO, Odenei de Souza. Tradição e modernidade no pensamento de Leandro Tocantins. Manaus: Tese (Doutorado em Sociedade e Cultura na Amazônia) — Universidade Federal do Amazonas, 2012. 326 f.

RODRIGUES, W. A.; SILVA, M. F.; SILVA, A. S. ; RIBEIRO, M. N.G. Criação e evolução bistórica do INPA. Acta Amazonica, Belém. Pará, 11 (1):723, 1981.

SANTOS, Paulo Roberto Elian dos. A arquivistica no laboratório: história, teoria e métodos de uma disciplina. São Paulo: Tese (Doutorado - Programa de Pós]graduação em História Social do Departamento de História) - Faculdade de Filosofia, Letras e Ciências Humanas da Universidade de São Paulo, 2008. 
SILVA, Maria Celina Soares Mello e (Org.). Arquivos científicos: referências bibliográficas. Rio de Janeiro: Museu de Astronomia e Ciências Afins, 2005.

SOUSA, Lademe Correia de. Arthur Reis e a História do Amazonas: um início em grande estilo. Dissertação de Mestrado. Manaus (Programa de PósGraduação em História), UFAM, 2009, $146 f$.

SOUZA, Márcio. História da Amazônia. Manaus: Editora Valer, 2009. 